\title{
Inhibition growth of pomegranate seeds extract against streptococcus sanguis: the cause of recurrent aphthous stomatitis
}

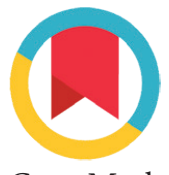

CrossMark

\author{
Riani Setiadhi, ${ }^{1 *}$ Irna Sufiawati, ${ }^{1}$ Dewi Zakiawati, ${ }^{1}$ \\ Nanan Nur'aeny, ${ }^{1}$ Wahyu Hidayat, ${ }^{1}$ Dani R. Firman ${ }^{2}$
}

\section{Abstract}

Objective: Pomegranate (punica granatum L.) seeds contain high of phytonutrients and phytochemicals, rich in polyphenol antioxidants namely tannins and flavonoids which also have antibacterial activity. Streptococcus sanguis is a bacterium known as one of the factors causing Recurrent Aphthous Stomatitis (RAS). To examine the potential antibacterial of pomegranate seeds against $S$. sanguis.

Material and Methods: In vitro study of pomegranate seed were extracted with maceration method using $70 \%$ ethanol as the solvent to obtain stable extract, continued with phytochemical screening against phenolic, flavonoids, alkaloids, steroids, triterpenoid, saponins and tannins. The extract was evaluated for Minimum Inhibitory
Concentration (MIC) and Minimum Bactericide Concentration (MBC) against S. sanguis ATCC 10556, using microdiluted method through 96 wells microplate.

Results: Chlorhexidine was used as positive control while 70\% ethanol was used as solvent as well as negative control. Phytochemical screening gave positive results for phenolics, flavonoids, steroids, saponins and tannins. Microdilution test showed the concentration of $500 \mathrm{ppm}$ as MIC and MBC value at $2000 \mathrm{ppm}$.

Conclusion: Pomegranate seeds extract have a growth inhibitory against S. sanguis with MIC value of $500 \mathrm{ppm}$ and $2000 \mathrm{ppm}$ as MBC.
'Department of Oral Medicine, Faculty of Dentistry, Padjadjaran University, Bandung, Indonesia 2Department of Oral Biology, Faculty of Dentistry, Padjadjaran University, Bandung Indonesia
*Correspondence to: Riani Setiadhi, Department of Oral Medicine, Faculty of Dentistry, Padjadjaran University

riani.setiadhi@unpad.ac.id

Keywords: Pomegranate seeds, Streptococcus sanguis, Recurrent aphthous stomatitis

Cite this Article: Setiadhi R, Sufiawati I, Zakiawati D, Nur'aeny N, Hidayat W, Firman DR. 2017. Inhibition growth of pomegranate seeds extract against streptococcus sanguis: the cause of recurrent aphthous stomatitis. Journal of Dentomaxillofacial Science 2(1): 7-11. D0I:10.15562/

jdmfs.v2i1.452

\section{Introduction}

Recently people start to choose herbs as medicine to cure various diseases because it is affordable and also quite efficacious. Pomegranate (punica granatum L.) is a long-living tree native from the Middle east, cultivated in the subtropical to the tropic regions. ${ }^{1}$ It has many benefits for health and usefulness as traditional medicine, used in several systems of medicine for a variety of ailments. In Indonesia as one of the country in the tropic region, Pomegranate is easy to grow in the home yard as well as an ornamental plant at the lowland to below $1000 \mathrm{~m}$ dpi region.

Pomegranate is a very versatile fruit which can be directly eaten fresh, or made as juice. It contains of high phytonutrient and phytochemical as well as rich in tannin antioxidant. Antioxidant is very beneficial for maintaining health and treating diseases. The main antioxidant in pomegranate is polyphenol which contains flavonoids, tannins and vitamin C. Besides as antioxidant, flavonoids, tannins also have antibacterial action. Jurenka ${ }^{1}$ stated the therapeutically beneficial pomegranate constituents are ellagic acid ellagitannins (including punicalagins), punicic acid, flavonoids, anthocyanidins, anthocyanins and estrogen flavonols and flavones. ${ }^{1}$ In Ayurvedic medicine the pomegranate is considered as "a pharmacy unto itself" and is used as an antiparasitic agent, a "blood tonic" and to heal aphthae, diarrhea and ulcers. ${ }^{1}$ The MIC of adherence of pomegranate against S. mitis, S. mutans, S. sanguis and C. albicans. $^{2}$

In daily life there are certain people who often have lesions in their mouth and people call it as aphthae. Medically this lesion known as Recurrent Aphthous Stomatitis (RAS), can occur at any part of the oral cavity accompanied with pain and may occur recurrently. It is a mild disease and not life threatening, self healing within 10-14 days without treatment but may interfere with eating and talking that can decrease the quality of life. ${ }^{3.5}$ Scully ${ }^{6}$ stated that the number of RAS incidence of about $10-25 \%$ in a population. It is a quite large number, so it is relevant if many researchers tried to find the best treatment for RAS. ${ }^{6}$

The etiology of RAS is still unknown, but there are some predisposing factors which were thought played an important role. Those factors are local factors, allergy, bacteria, immune status, haematinic, hormonal and psychological stress. 
One of the bacteria suspected as the cause RAS is S. sanguis. ${ }^{6,7}$

Until now only a few studies about pomegranate were reported, especially the study of the seeds as a drug that can inhibit the growth of bacteria S. sanguis in RAS. The purpose of this study was to find out the MIC and MBC of pomegranate seeds extract against bacteria in RAS S. sanguis.

\section{Material and Methods}

Pomegranate (punica granatum L.) fruits used in this study were obtained from the farmers' gardens in Cisarua Lembang, Indonesia. Standard S. sanguis (ATCC 10556) strains were used. The study was conducted at The Chemical Laboratory, Padjadjaran University. The process was started with preparing the material and plant determination i.e dried the pomegranate seeds under the sun, mashed it into powder and subjected to extraction with $70 \%$ ethanol. The powder were soaked in $70 \%$ ethanol as the solvent for 24 hours, the macerat were screened then evaporated with the rotary evaporator to obtained a stable extract. Then it was continued with phytochemical screening against phenolic, flavonoids, alkaloids, steroids,

\section{Table 1 Screening of secondary metabolites}

\begin{tabular}{lllc}
\hline No. & Secondary metabolites & Test method & The results \\
\hline 1. & Phenolic & $\mathrm{FeCl}_{3} 5 \%$ Reagent & + \\
2. & Flavonoids & $\mathrm{HCl}$ conctr $+\mathrm{Mg}$ Reagent & + \\
& & $\mathrm{H}_{2} \mathrm{SO}_{4} 2 \mathrm{~N}$ Reagent & + \\
& & $\mathrm{NaOH} 10 \%$ Reagent & - \\
3. & Alkaloids & Dragendorf Reagent & - \\
4. & Steroids & Lieberman-Burchard Reagent & + \\
5. & Triterpenoids & & - \\
6. & Saponnins & $\mathrm{HCl}_{2} \mathrm{H}_{2} \mathrm{O}$ Reagent & + \\
7. & Tannins & $\mathrm{FeCl}_{3} 1 \%$ Reagent & + \\
\hline
\end{tabular}
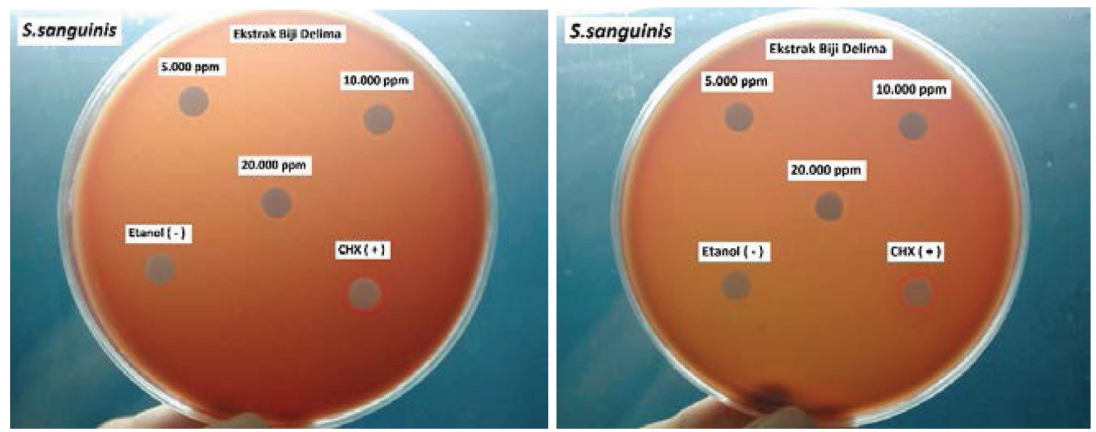

Figure 1 Antibacterial test analysis of Pomegranate seeds extract against S. sanguis triterpenoid, saponins and tannins. The next step was to determine the MIC and MBC of pomegranate seeds extract against $S$. sanguis ATCC 10556 through several stages i.e bacteria rejuvenation procedures, made the Mueller Hinton broth, determined the Optical Density (OD), antibacterial test with Disk Diffusion Test. The determination of MIC was carried out using microdiluted method through 96 wells microplate. Every two rows of wells duplodata was used namely media and samples in series 1 and 2 . The media and the solvent on a series 3 and 4 media, sample and bacteria $S$. sanguis in series 5 , 6 and on series 7, 8 were filled with media, solvents and the bacteria $\mathrm{S}$. sanguis. Chlorhexidine was used as positive control while $70 \%$ ethanol as the solvent as well as negative control.

\section{Results}

The weight of pomegranate seeds powder sample was 364 gram, after three steps of maceration process with $70 \%$ ethanol, 37.14 gram of extract were obtained. The depreciation value was $10.2 \%$.

Phytochemical tests was performed after Pomegranate seed extract were obtained. It was proposed to identify the content of secondary metabolites which was presented in the sample. The phytochemical screening showed positive result for phenolic, flavonoids, steroids, saponnins and tannins table 1.

The next step was assessing the extract for the MIC and MBC against S. sanguis. The result of inhibitory test showed that there was antibacterial activity marked by the formation of inhibition zone against $S$. sanguis table 2 and figure 1 .

According to the above table and figure, there were inhibition zones on pomegranate seed extract sample at the concentration of 20.000, 10.000 and $5000 \mathrm{ppm} .70 \%$ ethanol as the solvent was also act as negative control while chlorhexidine as positive control showed the inhibition zone at the concentration of $2000 \mathrm{ppm}$.

The results showed that there was inhibition activity against $\mathrm{S}$. sanguis of each concentration. That was the reason why it was necessary to do MIC test as the next step of anti-bacterial test. The MIC test was conducted using microdilution method through 96 well microplates. Every two rows of the wells using duplodata, which was media and sample in rows 1 and 2. The Media and solvent were in rows 3 and 4 . The media, sample and S. sanguis bacteria were in rows 5 and 6 . The media, solvent and S. sanguis bacteria were in rows 
Table 2 Antibacterial test analysis of pomegranate seeds extract against S. sanguis

\begin{tabular}{|c|c|c|c|c|c|}
\hline No & Sample \& Concentration (ppm) & Inhibitory Diameter, (d/mm) & \multicolumn{2}{|c|}{ D Average (mm) } & Note \\
\hline 1 & Punica granatum L. Seed Extract (20.000) & 8.40 & 8.15 & 8.28 & Active \\
\hline 2 & Punica granatum L. Seed Extract (10.000) & 8.10 & 8.70 & 8.40 & Active \\
\hline 3 & Punica granatum L. Seed Extract (5.000) & 8.10 & 7.80 & 7.95 & Active \\
\hline 4 & Control Negative: Ethanol solventPositive & - & - & - & Not Active \\
\hline 5 & Control: Chlorhexidine (2.000) & 11.30 & 11.40 & 11.35 & Susceptible \\
\hline
\end{tabular}

Table 3 MIC analysis of pomegranate seeds extract against S. sanguis

\begin{tabular}{lccccccccccccccccc}
\hline \multirow{2}{*}{ Well } & \multicolumn{10}{c}{ Concentration (ppm) } \\
\cline { 2 - 13 } & $\mathbf{8 . 0 0 0}$ & $\mathbf{4 . 0 0 0}$ & $\mathbf{2 . 0 0 0}$ & $\mathbf{1 . 0 0 0}$ & $\mathbf{5 0 0}$ & $\mathbf{2 5 0}$ & $\mathbf{1 2 5}$ & $\mathbf{6 2 , 5}$ & $\mathbf{3 1 , 2 5}$ & $\mathbf{1 5 , 6 3}$ & $\mathbf{3 , 8 1}$ & $\mathbf{3 , 9 1}$ \\
\hline \multirow{2}{*}{ Media + Sample } & 0.712 & 1.703 & 1.178 & 0.849 & 0.559 & 0.324 & 0.183 & 0.107 & 0.072 & 0.056 & 0.051 & 0.045 \\
& 0.574 & 1.237 & 1.013 & 0.601 & 0.368 & 0.218 & 0.134 & 0.084 & 0.061 & 0.051 & 0.045 & 0.043 \\
Media + Solvent & 0.042 & 0.039 & 0.038 & 0.041 & 0.040 & 0.042 & 0.040 & 0.040 & 0.040 & 0.043 & 0.041 & 0.041 \\
& 0.043 & 0.038 & 0.038 & 0.041 & 0.040 & 0.041 & 0.041 & 0.043 & 0.043 & 0.043 & 0.041 & 0.040 \\
Media + Sample + Bacteria & 0.623 & 1.045 & 0.890 & 0.596 & 0.367 & 0.216 & 0.134 & 0.100 & 0.095 & 0.092 & 0.083 & 0.079 \\
& 0.656 & 0.737 & 0.890 & 0.658 & 0.410 & 0.250 & 0.151 & 0.112 & 0.106 & 0.094 & 0.086 & 0.074 \\
Media + Solventt + Bacteria & 0.043 & 0.042 & 0.042 & 0.043 & 0.047 & 0.087 & 0.115 & 0.111 & 0.105 & 0.108 & 0.110 & 0.109 \\
& 0.045 & 0.044 & 0.044 & 0.046 & 0.047 & 0.084 & 0.095 & 0.105 & 0.101 & 0.106 & 0.110 & 0.107
\end{tabular}
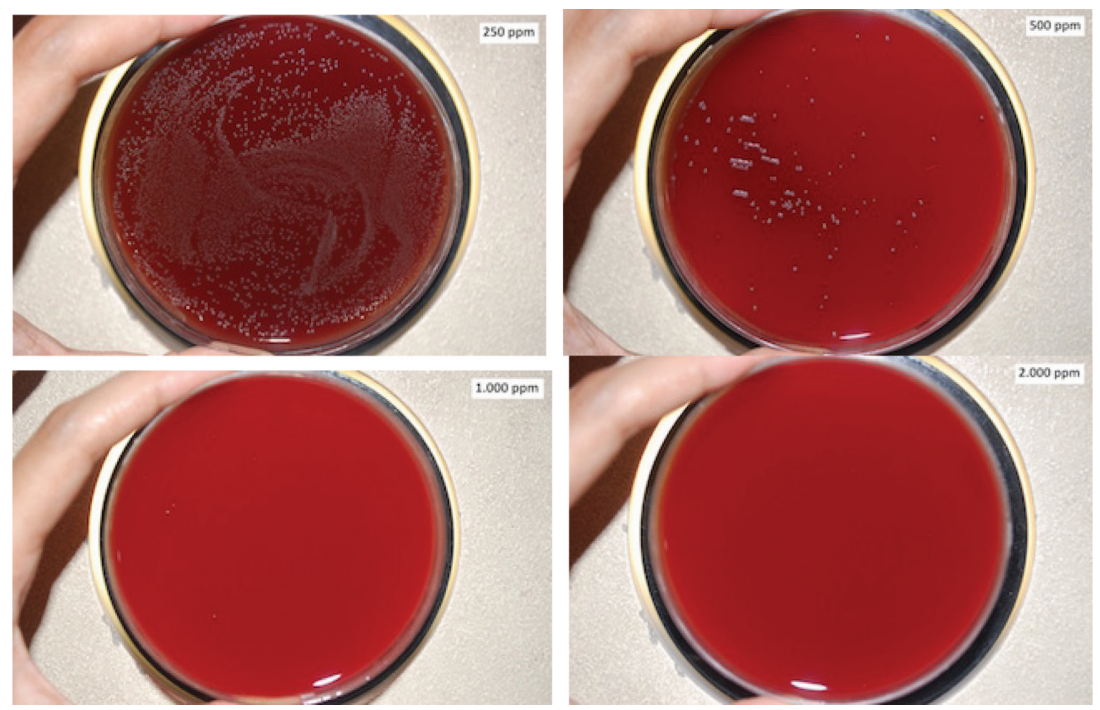

Figure 2 MBC value of pomegranate seeds extract against S. sanguis

7 and 8. Dilution carried out in stages, starting from the concentration of $32.000 \mathrm{ppm}$.

In table 3, along with the decrease in extract's concentration by the multiple of $1 / 2$, there was a growing in the number of bacteria at the concentration of $250 \mathrm{ppm}$ for wells consisting of media and sample. This condition provides that the value of MIC was before the concentration of $250 \mathrm{ppm}$, i.e at concentration of $500 \mathrm{ppm}$. Wells consisting of S. sanguis in media and solvent showed that there was S. sanguis growth at the concentration of $1000 \mathrm{ppm}$, it gave information that solvent had influence in $\mathrm{S}$. sanguis growth inhibition by MIC 2000 ppm.

Figure 2 the MBC determination test of Pomegranate seeds extract against $S$. sanguis showed there was still a growing of bacterial colonies at the concentration of 250, 500 and $1000 \mathrm{ppm}$, whilst in the subsequent concentration (2000 ppm) found no bacterial growth. It could be determined that $\mathrm{MBC}$ for pomegranate seeds extract against S. sanguis was on the value of 2000 ppm table 2.

\section{Discussion}

The important phytochemical test was conducted after the maceration process with $70 \%$ ethanol and pomegranate seeds extract were obtained. It is necessary to identify the content of the extract. The phytochemical screening results proved that pomegranate seeds extract contains of phenolics, flavonoids, steroids, saponins and tannins. The phenolics and flavonoids group have been known of its antibacterial activity. The former study stated that antimicrobial activity from 6 variety Pomegranate were correlated with the respond of phytonutrient substance, such as total phenolics and anthocyannins compound., 8

Phytochemical screening of pomegranate peel and leaf indicated alkaloids, tannins, sterol, volatile oil, carbohydrate, flavonoids, glycosid, resin, balsams, terpenes and Free-Reducing Sugar but 
saponins was undetectable. The content of these metabolites substances showed great potential as medicinal plant. ${ }^{10,11}$

The result of phytochemical test pomegranate seeds extract as a guide to do the next test i.e the test for S. sanguis inhibition. The phenolics and flavonoids group have been known to have antibacterial activity, that is why the result of phytochemical test could support if there were antibacterial properties during inhibition test (disk diffusion), MIC and MBC. ${ }^{12,13}$ MIC of an antimicrobial extract was determined using broth serial dilution technique as was done in this study, antimicrobial substance was diluted several times using tube test contained of nutrient compound and then reacted with the pathogenic bacteria. The tube test then incubated, the growth of pathogenic bacteria was detected using spectrophotometer $600 \mathrm{~nm}$. Concentration on the tube test which showed the bacterial growth increases dramaticallyexpressed as MIC. ${ }^{14}$

The result of this study showed that MIC of pomegranate seeds extract was $500 \mathrm{ppm}$ while MIC for media and solvent was $2000 \mathrm{ppm}$. It indicated that MIC value of pomegranate seeds extract was better and if the evaporation stage in maceration process had successfully vaporized the whole $70 \%$ ethanol as a solvent, the only remaining substance was active compound or thick extract. Even though if there was still little substance was left and carried out, the effect was not expected to change the MIC value which was obtained significantly.

Vasconcelos et al. ${ }^{15}$ stated that pomegranate peel extract can be used to control adherence of different microorganisms in the oral cavity. MIC of adherence of pomegranate gel against S. mutans and $\mathrm{S}$. sanguis were 1:16, 1:128 for $\mathrm{S}$. mitis and 1:64 for C. albicans. ${ }^{15}$ MIC adherence of pomegranategel against S. mitis (1:512), S. mutans (1:256), S. sanguis (1:128) and C. albicans (1:4). ${ }^{16}$

There were differences between the MIC against S. sanguis then MIC was $500 \mathrm{ppm}$ the MIC was $1: 16 \quad(62.500 \mathrm{ppm})$ and 1:128 (7800 ppm) espectively. These differences occur because the pomegranate extract used in this study was derived from the seeds. The result of this study indicated that MIC of pomegranate seeds extract was better than peel's extract.
The value of the lowest concentration of pomegranate seeds extract was known, could inhibit the growth of S. sanguis bacteria MIC. The next step was determining the MBC value. MBC is the lowest concentration of an antimicrobial that will prevent the growth of organisms in a culture broth. ${ }^{16}$ The determination test for $\mathrm{MBC}$ value of pomegranate seeds extract indicated that at the concentration of 250, 500 and $1000 \mathrm{ppm}$ there were still bacterial colonies growth, while at the subsequent concentration of $2000 \mathrm{ppm}$ no growth of colony bacteria, thus $\mathrm{MBC}$ value for pomegranate seeds extract sample against $\mathrm{S}$. sanguis was at the value of $2000 \mathrm{ppm}$.

\section{Conclusion}

Pomegranate seeds extract has proven containing phenolics, flavonoids, steroids, saponins and tannins at phytochemical test and has bacteriostatic activity against S. sanguis with 500 ppm as MIC value and bactericidal MBC at the concentration of $2000 \mathrm{ppm}$.

\section{Acknowledgment}

The researchers would like to thank to the research unit especially to the Dean of Faculty of Dentistry, Padjadjaran University and staffs for this immense opportunity and for funding provided for us to conduct this study.

Our colleagues and Laboratory staffs at The Chemical Laboratory, Padjadjaran University who have made an invaluable contribution to the research, therefore we are never enough to thank them. Finally, we are grateful for the support of our families during the preparation of this study.

\section{Conflict of Interest}

The authors report no conflict of interest.

\section{References}

1. Jurenka, J. Therapeutic applications of Pomegrante (Punica granatum L.): A Review. Altern Med Rev 2008;13: 128-131.

2. Jozinete VP, Maria SVP, Fábio CS, et al. In vitro antibacterial and antiadherence effect of Punica Granatum linn extract upon dental Biofilm microorganisms. Rev Braz Farmacogn 2006;16: 88-93.

3. Greenberg M, Ulcerative, Vesicular, et al. Burket's Oral Medicine. 10th ed. Spain: BC Decker; 2003. p. 63-65.

4. Field A, Lesley L, William RT. Tyldesley's Oral Medicine. 5th ed. Oxford: Oxford University Press; 2004. p. 49-60. 
5. Preeti L, Magesh KT, Rajkumar K, et al. Recurrent Aphthous Stomatitis. J Oral Maxillofac Pathol 2011;15: 252-256.

6. Scully C, Porter S. Orofacial disease. 1st ed. Edinburgh: Churchill Livingstone; 2003. p. 13-15.

7. Scully C. Oral and Maxillofacial medicine the basis of diagnosis and treatment. 2nd ed. Edinburgh: Churchill Livingstone Elsevier; 2008. p. 12.

8. Anibal PC, Peixoto ITA, Foglio MA, et al. Antifungal activity of the Ethanolic extracts of Punica Granatum L and evaluation of the Morphological and structural modifications of its compounds upon the cells of Candida sp. Braz J Microbiol 2013;44: 839-848.

9. Duman AD, Ozgen M, Dayisoylu KS, et al. Antimicrobial activity of six Pomegranate (Punica granatum L.) varieties and their relation to some of their Pomological and Phytonutrient characteristics. Molecules 2009;14: 1808-1817.

10. Egharevba, Omoregie H, Kunle et al. Phytochemical analysis and antimicrobial activity of Punica Granatum L. (fruit bark and leaves) N Y Sci J 2010;12: 3.

11. Abdollahzadeh Sh, Mashouf RY, Mortazavi H, et al. Antibacterial and antifungal activities of Punica Granatum
Peel extracts against Oral Pathogens. J Dent (Tehran) 2011;8: 1-6.

12. Saravanakumar A. Evaluation of antibacterial activity Phenol and flavonoid contents of the Spesiapulnea flower extracts. Pak J Pharm Sci 2013;22: 283-286.

13. Karamian R, Ghasemlou F. Screening of total phenol and flavonoid content, antioxidant and antibacterial activities of the Methanolic extracts of three Silene species from Iran. IJACS 2013;5: 305-312.

14. Hanee S, Khan JA. Antibacterial properties of Punica granatum Peel. Int J Appl Biol Pharm 2011;2: 23-27.

15. Vasconcelos LCD, Sampaio FC, Sampaio MCC, et al. Minimum inhibitory concentration of adherence of Punica granatum Linn (Pomegranate) gel against S. Mutans, S. Mitis and C. Albicans. Braz Dent J 2006;17: 223-227.

16. Andrews JM. Determination of minimum inhibitory concentrations. J Antimicrob Chemother 2001;48: 5-16.

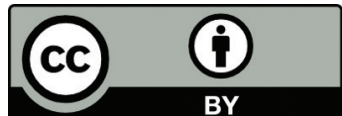

This work is licensed under a Creative Commons Attribution 